\title{
Malaria epidemiology in low-endemicity areas of the northern coast of Ecuador: high prevalence of asymptomatic infections
}

\author{
Fabián E. Sáenz ${ }^{1 *} \mathbb{D}$, Andrea Arévalo-Cortés ${ }^{1}$, Gabriela Valenzuelaํ, Andrés F. Vallejo ${ }^{2}$, Angélica Castellanos², \\ Andrea C. Poveda-Loayza', Juan B. Gutierrez³, Alvaro Alvarez ${ }^{4}$, Yi Heng Yan³ ${ }^{3}$ Yoldy Benavides ${ }^{4}$, \\ Luis Enrique Castro ${ }^{5}$, Myriam Arévalo-Herrera ${ }^{2,6}$ and Sócrates Herrera ${ }^{2}$
}

\begin{abstract}
Background: The recent scale-up in malaria control measures in Latin America has resulted in a significant decrease in the number of reported cases in several countries including Ecuador, where it presented a low malaria incidence in recent years (558 reported cases in 2015) with occasional outbreaks of both Plasmodium falciparum and Plasmodium vivax in the coastal and Amazonian regions. This success in malaria control in recent years has led Ecuador to transition its malaria policy from control to elimination.

Results: This study evaluated the general knowledge, attitude and practices (KAP) about malaria, as well as its prevalence in four communities of an endemic area in northwest Ecuador. A total of 258 interviews to assess KAP in the community indicated that most people in the study area have a basic knowledge about the disease but did not use to contribute to its control. Six hundred and forty-eight blood samples were collected and analysed by thick blood smear and real-time PCR. In addition, the distribution of the infections was mapped in the study communities. Although, no parasites were found by microscopy, by PCR the total malaria prevalence was $7.5 \%$ (6.9\% P. vivax and $0.6 \%$ P. falciparum), much higher than expected and comparable to that reported in endemic areas of neighbouring countries with higher malaria transmission. Serology using ELISA and immunofluorescence indicated $27 \%$ respondents for $P$. vivax and $22 \%$ respondents for $P$. falciparum.
\end{abstract}

Conclusions: Results suggest that despite a great malaria reduction in Ecuador, transition from control to elimination would demand further improvement in malaria diagnostics, including active case detection to identify and treat parasite asymptomatic carriers, as well as community participation in its elimination.

Keywords: Asymptomatic malaria, Ecuador, Knowledge attitude and practices, Elimination

\section{Background}

Malaria is endemic in the coastal and Amazon regions of Ecuador in areas below $1500 \mathrm{~m}$ of altitude, however, the number of malaria cases has decreased $>99 \%$ since 2001 and only 558 cases were reported in 2015 (Fig. 1); [1]. During the last 10 years, malaria control efforts have been highly effective and according to the Pan American

\footnotetext{
*Correspondence: fsaenz213@puce.edu.ec

${ }^{1}$ Centro de Investigación para la Salud en América Latina, Escuela de Ciencias Biológicas, Pontificia Universidad Católica del Ecuador, Calle Pambacienda y San Pedro del Valle, Quito, Ecuador

Full list of author information is available at the end of the article
}

Health Organization (PAHO), the country is currently in malaria pre-elimination phase $[2,3]$, closer to elimination than its neighbours Colombia and Peru. According to the World Health Organization, Ecuador is among the 21 countries that are in track for malaria elimination in 2020 [4]. Ecuador is focusing in fast detection of acute malaria clinical cases and treatment with artemether-lumefantrine (Plasmodium falciparum) and chloroquine + primaquine (Plasmodium vivax). Malaria surveillance activities are focused in the Northwest coast and in the Amazon regions, the current endemic areas [2]. 


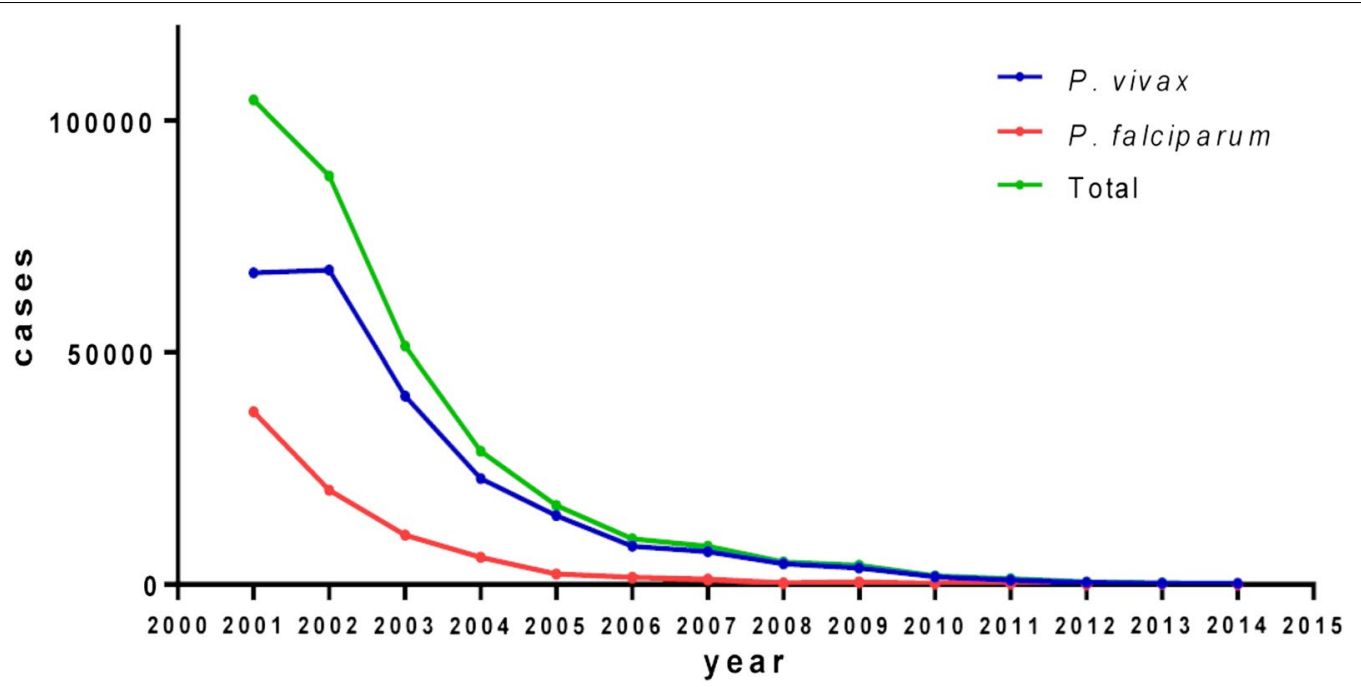

Fig. 1 General trend of malaria in Ecuador 2001-2014. A 99\% decrease in malaria cases is shown since the year 2001 for total cases (green line) as well as those caused by each of the main parasite species: P. vivax (blue line) and P. falciparum (red line)

Presently transmission is low and unstable with periodic outbreaks of both $P$. falciparum and $P$. vivax, still occurring on both sides of the Andes [1,5]. The northwest coast of Ecuador, particularly Esmeraldas province, which limits on the North with the Nariño department of Colombia has historically been an area of P. falciparum transmission [5]. Although this region has experienced a substantial decrease in the number of reported malaria cases, it still maintains transmission and in the 2012-2013 period, it reported an outbreak of $150 \mathrm{P}$. falciparum cases in Esmeraldas city $[5,6]$. In contrast, during the same period, San Lorenzo which historically had reported the highest $P$. falciparum annual parasite incidence (API) reported only $\sim 20$ cases [6]. In 2014 only 20 malaria cases were reported in Esmeraldas province but $>100$ cases were reported in both 2015 and 2016 [1].

Despite the low transmission, several challenges remain for Ecuador to progress towards the elimination goal. Major challenges are the accurate estimation of malaria prevalence, particularly in view of the number of asymptomatic cases potentially harbouring low levels of parasitaemia not detectable by microscopic examination and the instability of malaria control activities. As in many other regions, microscopic examination of thick blood smears is the gold standard for malaria diagnosis due to its good performance to confirm symptomatic infections. However, many infections have been shown to be submicroscopic and asymptomatic [7], leading to an underestimation of the number of infected individuals in endemic communities. These latter cases remain in the communities as parasite reservoirs for mosquito infection and require active case search as well as the use of more sensitive diagnostic methods. Although asymptomatic infections are considered to be the result of incremental immunity due to frequent exposure to parasite infections, and to reduce the disease burden, they contribute to maintaining malaria transmission [7-10]. Although a growing number of studies have estimated the prevalence of asymptomatic cases in diverse areas of Latin America such as Brazil, Colombia and Peru, as well as in regions in other continents with greater transmission intensities such as the Solomon Islands and Papua New Guinea (PNG) [7, 11-13], the proportion of asymptomatic malaria carriers in Ecuador has not been reported, leading to an underestimation of the real malaria incidence. This knowledge gap as well as others concerning the biology of vectors have to be addressed in malaria elimination programmes. Although Anopheles albimanus is considered the main vector species in northern Ecuador and southwest Colombia [14], the knowledge on its bionomy and potential vectors is limited $[15,16]$. These knowledge gaps must be addressed for malaria elimination programmes.

The aim of this study was to better understand the epidemiological situation in the northern region of Ecuador, in view of the current malaria elimination plans. Four communities of Esmeraldas province were investigated by using sociodemographic and epidemiological surveys.

\section{Methods}

Study area

Four endemic settings in Ecuador's San Lorenzo canton in Esmeraldas province were selected because of the relatively higher malaria prevalence, as compared 
to other parts of the country: El Pedregal, Ricaurte, La Boca, and El Guadual. All are located close to the road between Ibarra and San Lorenzo city (Fig. 2). Plasmodium vivax and $P$. falciparum are both transmitted in different proportions in these regions, which display an unstable transmission pattern. Pedregal is a semi-urban neighbourhood of the city of San Lorenzo, has a population of 270 inhabitants, and is located at sea level. Most inhabitants are described as African-Ecuadorians. The predominant malaria parasite species in this area is $P$. falciparum (six cases in 2013). Ricaurte is a semi-urban community in the Tululbí River $15 \mathrm{~km}$ southeast of El Pedregal; it has a population of 1300 inhabitants. La Boca is a rural community located $10 \mathrm{~km}$ southeast of Ricaurte at sea level, in the intersection of the Bogotá and Tululbí rivers; it has a population of 580 inhabitants predominantly African-Ecuadorian; El Guadual is a rural community located $40 \mathrm{~km}$ southeast of La Boca in the common border of Esmeraldas, Carchi, and Imbabura provinces; it is located at a higher altitude $(600$ m.a.s.l) and it has a population of 250 inhabitants predominantly mestizo; sporadic cases of $P$. vivax and $P$. falciparum have been previously reported in this community. A summary of the geographic and demographic characteristics of the study sites is shown in Table 1.

\section{Sample collection}

A total of 649 individuals living in 258 houses of the study communities were studied. Blood samples were randomly chosen from residents of the four communities using the software Epidat to obtain a 95\% confidence. Samples were collected in El Pedregal (177), Ricaurte

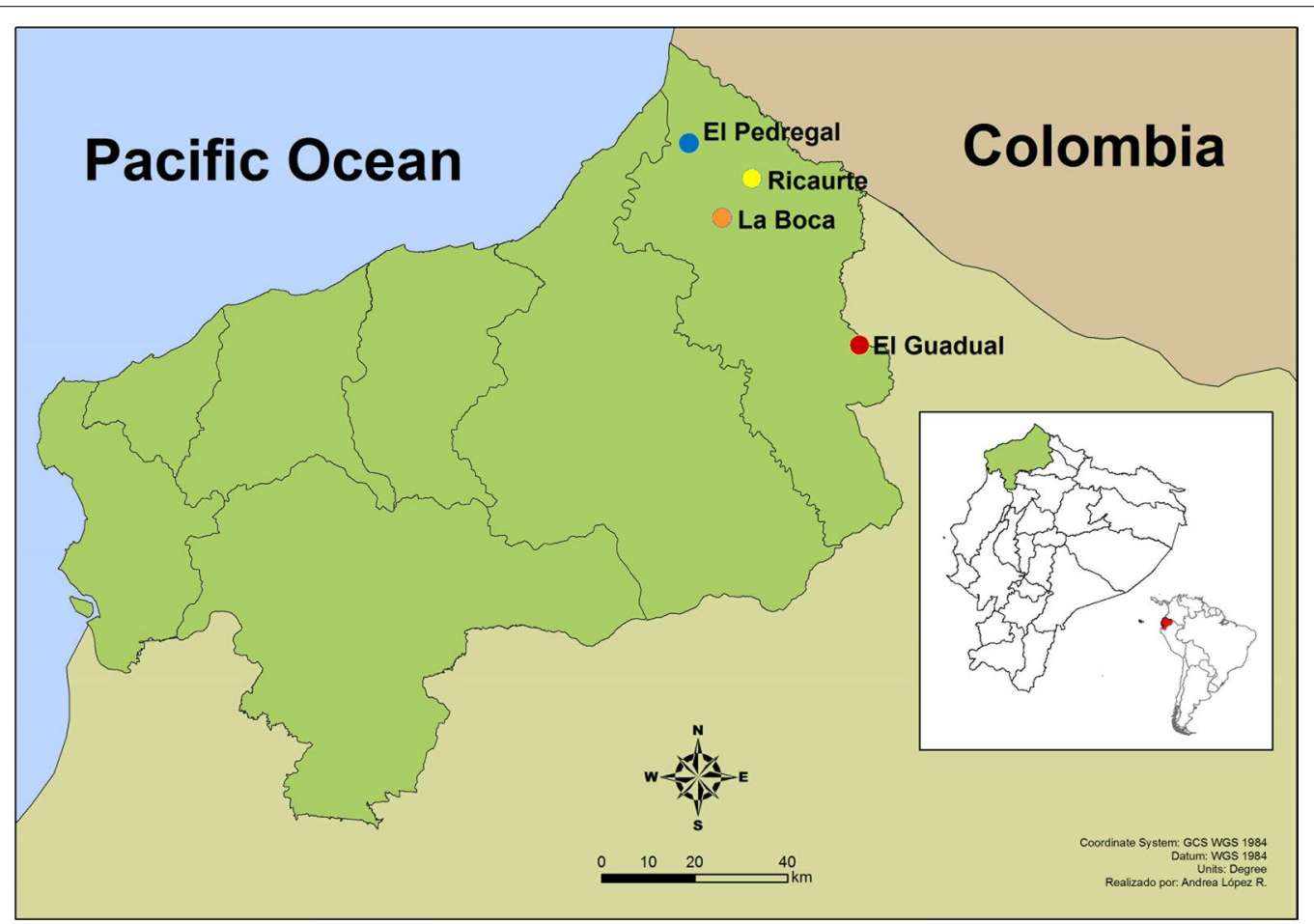

Fig. 2 Study area. The study was performed in four locations in the Esmeraldas province (green) in Ecuador (red) which are indicated by color dots on the map

Table 1 Study communities: geographical and population characteristics

\begin{tabular}{lcllclc}
\hline Locations & $\begin{array}{l}\text { Altitude } \\
\text { (m.a.s.l) }\end{array}$ & $\begin{array}{l}\text { Average yearly } \\
\text { rainfall }(\mathbf{m m})\end{array}$ & $\begin{array}{l}\text { Average } \\
\text { temperature }\left({ }^{\circ} \mathbf{C}\right)\end{array}$ & $\begin{array}{l}\text { Population } \\
\text { (inhabitants) }\end{array}$ & $\begin{array}{l}\text { Community } \\
\text { type }\end{array}$ & Dominant ethnicity \\
\hline El Pedregal & 9 & 2549 & 26.0 & 240 & Semi-urban & African-Ecuatorians \\
Ricaurte & 20 & 2553 & 25.9 & 1300 & Semi-urban & African-Ecuatorians \\
La Boca & 21 & 2474 & 26.0 & 580 & Rural & African-Ecuatorians \\
El Guadual & 600 & 2544 & 25.6 & 250 & Rural & Mestizo \\
\hline
\end{tabular}


(231), La Boca (165), and El Guadual (73). The blood was collected by finger prick and spotted on filter paper (Whatman 3MM) from inhabitants aged 2-70 years old. In addition, thin and thick blood smears were taken from each individual. All houses where georeferenced and geolocalized in a map.

\section{KAP evaluation}

A simple KAP questionnaire was designed, approved by the Ethical Review Committees and used to survey a sample of the population. The questionnaire had a total of 13 questions: four questions of general knowledge about malaria transmission, three about prevention of malaria and six about malaria history.

\section{Ethical statement}

The study protocol was approved by the Ethical Review Committees of Pontificia Universidad Catolica del Ecuador (\# CBE-016-2013). Written informed consent (IC) was provided by study participants and/or their legal guardians (informed assent) for both the KAP survey and sample collection.

\section{Parasitological tests \\ Microscopy}

The thin and thick blood smears taken from each individual were stained by the standard Giemsa method and used to confirm malaria infection [17]. Parasite densities were determined by using an optical microscope with $100 \times$ magnification and counting the number of parasites present in 400 white blood cells (WBC) at different fields and read by two independent microscopists. The total number of parasites per $\mu \mathrm{l}$ was estimated assuming patients had a WBC count of $8000 / \mu l$. Thin smears were used for Plasmodium species confirmation.

\section{Real time PCR ( $q P C R$ )}

DNA was extracted using the PureLink Genomic DNA Mini Kit (Life Technologies, USA), and real time PCR was performed as previously described $[13,18,19]$, using primers targeting the $18 \mathrm{~S}$ rRNA gene. Standard $P$. falciparum and $P$. vivax DNA positive and negative controls were used in each batch of tests including the extraction of both negative and inhibition control. A sample was considered negative if there was no increase in the fluorescent signal after a minimum of 40 cycles. Parasitaemia quantification was performed using a parasite specific standard curve made with serial blood dilutions of a reference field isolate. Each reaction plate included a standard curve for parasite quantification and positive results were independently confirmed. All positive results were reported to the local health authorities.

\section{Serological assays}

The serum was extracted from blood samples on filter paper as previously described [20]. The dried samples were cut out (two circles of $3 \mathrm{~mm}$ ), placed in $1.5 \mathrm{ml}$ tubes and eluted in a stationary manner in $1 \mathrm{ml}$ of PBS/0.05\% Tween 20 overnight at $4{ }^{\circ} \mathrm{C}$. Eluted serum was used to determine anti-malarial antibodies using both indirect immunofluorescence (IFAT) and enzyme linked-immunofluorescence assay (ELISA) methods.

For IFAT, $P$. falciparum or $P$. vivax infected red blood cells were used to produce antigen slides, which were processed as previously described [21]. Serum samples were incubated at 1:10 or 1:20 dilution and labelled with fluorescein isothiocyanate (FITC) conjugated-affinity goat-human IgG antibody at 1:1500 dilutions. Slides were examined under an epifluorescence microscope. For ELISA both $P$. vivax and $P$. falciparum antigens were used as follows: for $P$. vivax a long synthetic peptide corresponding to the amino terminus of the circumsporozoite (CS) protein (CS-N) and an amino terminal recombinant fragment (r200L) of the merozoite surface protein 1 (MSP-1); for P. falciparum a synthetic fragment corresponding to the amino flank (CS-N fragment) was used. These antigens have been previously shown to be highly immunogenic [22-25]. IgG against pre-erythrocytic $P$. vivax and asexual blood stages antigens of both $P$. vivax and $P$. falciparum were determined by ELISA as described elsewhere [22]. Briefly, 96-well plates (NuncImmuno Plate, Maxisorp, Roskilde, Denmark) were coated overnight with recombinant or synthetic protein fragments at $1.0 \mu \mathrm{g} / \mathrm{ml}$ and then blocked with $5 \%$ skim milk in PBS 1X, 0.05\% Tween20 (PBS-T) for $1 \mathrm{~h}$ at room temperature. Test sera diluted 1:200 in $2.5 \%$ skim milk in PBS-T were then incubated for $1 \mathrm{~h}$ at $37{ }^{\circ} \mathrm{C}$. After washing, the plates were incubated for $1 \mathrm{~h}$ at $37^{\circ} \mathrm{C}$ with a 1:1000 or 1:2000 dilution of alkaline phosphatase-conjugated goat anti-mouse/human IgG antibody (Sigma Chemical Co., St Louis, MO). Cut-off points for ELISA were calculated as three SD above the mean absorbance value at $405 \mathrm{~nm}$ of normal human sera from healthy adult volunteers who had never been exposed to malaria. The results were also expressed as reactivity index (RI) defined as OD values of tested samples divided by the cut-off value.

\section{Statistical analysis Data entry}

Study data were collected and managed using REDCap electronic data capture tools hosted at the Caucaseco Research Center, Cali, Colombia [26]. REDCap (Research Electronic Data Capture) is a secure, web-based application designed to support data capture for research 
studies, providing: (1) an intuitive interface for validated data entry; (2) audit trails for tracking data manipulation and export procedures; (3) automated export procedures for seamless data downloads to common statistical packages; and (4) procedures for importing data from external sources. Data analysis was conducted with MATLAB release 2012b. Chi square statistical test was used to categorize malaria knowledge and practices, antibody frequencies and the parasitological prevalence.

\section{Spatial analysis of malaria cases in the study area}

To generate a smooth representation of the discrete malaria case data collected during the study, a Gaussian kernel estimator was used to produce a population density map, a disease incidence map and a disease risk map per each village in the study. The population data of each village was smoothed using a Gaussian kernel estimator where the surveyed population data per household were treated as samples $\left(\mathrm{X}_{1} ; \mathrm{X}_{2}, \ldots, \mathrm{Xn}\right)$ drawn from some unknown distribution $\mathrm{f}(\mathrm{y})$, where $\mathrm{y}$ is a geographical coordinate. $X_{i 1}$ is the latitude of the sample and $X_{i 2}$ is the longitude of the sample. To estimate the shape of this distribution $\mathrm{f}$, we used a Gaussian kernel with bandwidth $h_{1}$ of 0.0005 longitude and $h_{2}$ of 0.0005 latitude. Where the density of the function $f(y)$ is estimated using the following expression:

$$
f(y)=\frac{1}{n} \sum_{i=1}^{n} \frac{1}{h_{1}} \frac{1}{h_{2}} K\left(\frac{y_{1}-x_{i 1}}{h_{1}}\right) K\left(\frac{y_{2}-x_{i 2}}{h_{2}}\right) .
$$

Before producing the contour plot of the smoothed population data, a convex hull was produced to estimate the area of each village. The disease incidence data per each village was also smoothed using a Gaussian kernel estimator and a contour plot was produced and cropped using the same convex hull for the population distribution of each village. Finally, the disease risk map was produced by dividing the value of each point in the disease incidence map by the value of each point in the population distribution map.

\section{Results}

\section{KAP survey}

The general malaria KAP survey was performed on a sample of the population ( $\mathrm{n}=258$ houses), and one person was surveyed in each house. In terms of knowledge, it was found that only a small percentage of the population (5-10\%) see malaria as the main health problem that affects their communities when compared to other diseases such as respiratory diseases. In addition, 50-75\% of the surveyed people in the communities declared to know how malaria is transmitted and $90-100 \%$ knew that a mosquito is responsible for malaria transmission.
Likewise, most surveyed people (60-75\%) correctly identified the main symptoms of malaria such as fever and headache. Only in El Guadual, most families identified chills as an important symptom. This was significantly different from the other three communities $(P=0.02)$. Regarding malaria prevention practices, $>90 \%$ of the surveyed families identified the use of bed nets and closing doors and windows as the main activities to prevent malaria, while other activities such as use of mosquito repellent and insecticide-treated bed nets were not as commonly recognized except by families in El Pedregal $(P=0.04)$. A small proportion of the families $(10-30 \%)$ indicated to take actions against malaria outside of the house like cleaning grass and bushes.

\section{Prevalence of Plasmodium infections}

Six hundred and forty-eight thick and thin blood smear slides from the four study communities were analysed by optical microscopy. All were negative for the presence of Plasmodium parasites, however, when analysed by qPCR a mean overall prevalence of $7.4 \%$ Plasmodium infections was confirmed in the study area. The positivity rate for each community was $13 \%$ for El Pedregal, $2 \%$ for Ricaurte, $10 \%$ for La Boca and 5\% for El Guadual. Among the qPCR positive volunteers, only one presented symptoms resulting in $98 \%$ asymptomatic infections.

The most prevalent parasite was P. vivax with $6.9 \%$ prevalence in the study communities (13\% in El Pedregal, 1.3\% in Ricaurte, 9.7\% in La Boca, and $4.1 \%$ in El Guadual; Fig. 3). The parasitaemia levels varied between 1 parasite $/ \mu$ l and 813 parasites $/ \mu$ l. Among the four study populations, El Pedregal had a mean parasitaemia of 131.7 parasites/ $\mu \mathrm{l}$ (SD: 179.6), Ricaurte 36.75 (SD: 62.19), La Boca 16.59 parasites/ $\mu \mathrm{l}$ (SD: 23.37) and El Guadual 15 parasites/ $\mu$ l (SD: 6.73) (Fig. 3). El Guadual had the highest proportion of $P$. falciparum infections (1.4\%).

\section{Antibody responses}

A total of 646 individuals were evaluated for antibody levels against both parasite species. Overall, 48.77\% of volunteers presented antibodies against antigens of either $P$. vivax or $P$. falciparum. Specifically, $23.08 \%$ of volunteers presented antibodies against $P \nu \mathrm{CS}-\mathrm{N}, 27.23 \%$ against PvMSP1 (Pvr200L) and $21.69 \%$ against PfCSN. The community with a higher percentage of responders for all three antigens was El Pedregal (42\% responders for $P \nu \mathrm{CS}-\mathrm{N}, 36 \%$ responders for $P \nu \mathrm{MSP} 1$ and $44 \%$ responders for PfCS N), followed by La Boca (29\% responders for $P \nu \mathrm{CSN}, 38 \%$ responders for Pvr200L and 9\% responders for PfCS-N), and Ricaurte (10\% responders for $P \nu \mathrm{CSN}, 21 \%$ responders for $P \nu \mathrm{r} 200 \mathrm{~L}$ and $14 \%$ responders for PfCS-N). El Guadual had the lowest percentage of responders against two of the three antigens $(8 \%$ 


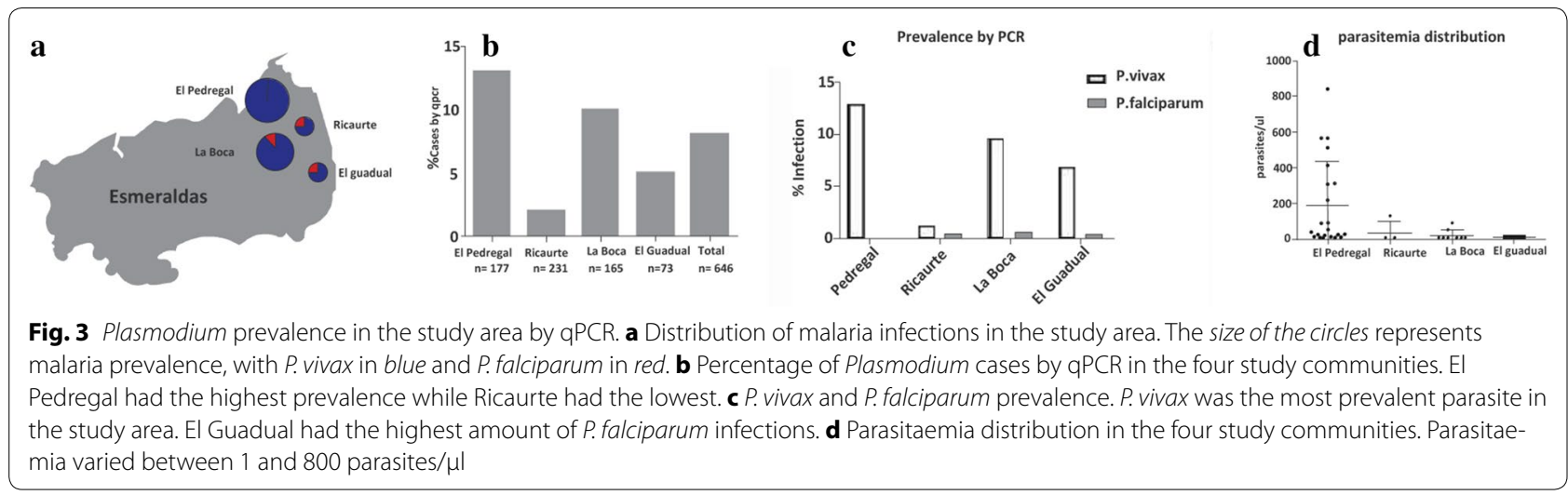

responders for $P \nu C S-\mathrm{N}, 3 \%$ responders for $P v \mathrm{MSP} 1$ and $22 \%$ responders for PfCS-N) (Fig. 4).

When looking at specific antigens for $P$. vivax and $P$. falciparum, there was an overall seroprevalence of $11 \%$ of respondents to both $P$. vivax antigens tested and a $9.4 \%$ of responders to the $P$. falciparum antigen CS-N. The community with the highest antibody prevalence was $\mathrm{El}$ Pedregal while the community with the least prevalence was El Guadual (Fig. 4). The IFAT performed with samples PCR positive for Plasmodium indicated $12.5 \%$ positive samples (Table 2).

\section{Malaria distribution map in study populations}

The human population distribution was used alongside with the case distribution to generate a geographical representation of malaria risk in El Pedregal, Ricaurte and La Boca (the number of surveyed houses in El Guadual was too small to generate a significant map). In La Boca there was a high concentration of malaria in places where the population density was low, thus clearly delineating an area of high risk (Fig. 5); this could suggest localized anopheline breeding sites, or a concentration of inhabitants with additional risk factors (e.g. occupational). In El Pedregal, malaria cases were more frequent in areas of higher human population density, thus, the risk was closely proportional to the human population. In Ricaurte, there was an area of low population density and high number of cases, thus creating a zone of increased risk as compared to the rest of the locality.

\section{Discussion}

Ecuador has experienced $\sim 99 \%$ reduction in malaria clinical cases in the last 15 years and is now pointing towards an elimination phase. Despite periodic focal outbreaks, the country has shown a malaria transmission decreasing trend. In 2014, Ecuador reported the lowest malaria incidence of the last decade but in 2016 the reported incidence (917 cases), almost doubled that of

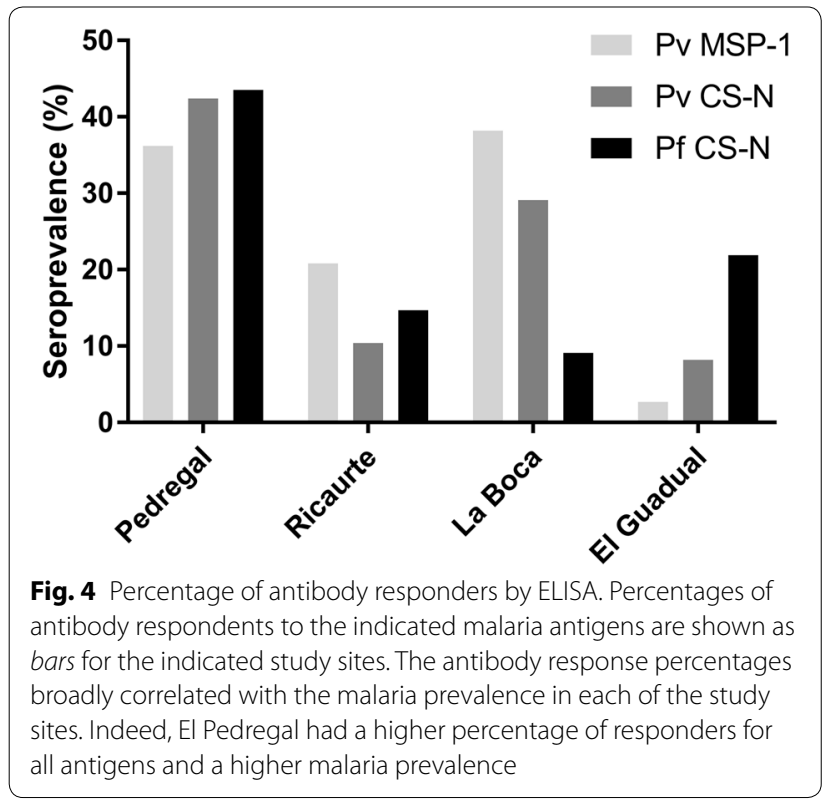

Table 2 IFA positivity in PCR positive samples

\begin{tabular}{lccc}
\hline Location & $\mathbf{n =}(\mathbf{P C R}+)$ & IFA positive & $\%$ \\
\hline El Pedregal & 23 & 22 & 96 \\
El Guadual & 4 & 2 & 50 \\
Ricaurte & 4 & 4 & 100 \\
La Boca & 17 & 14 & 82 \\
Total & 48 & 42 & $87.5^{*}$ \\
\hline
\end{tabular}

* Average percentages

the previous year. The study indicated the presence of a significant number of asymptomatic malaria parasite carriers in the study sites, with parasitaemia detectable only by qPCR which is probably an indication of an official under reporting of cases. 


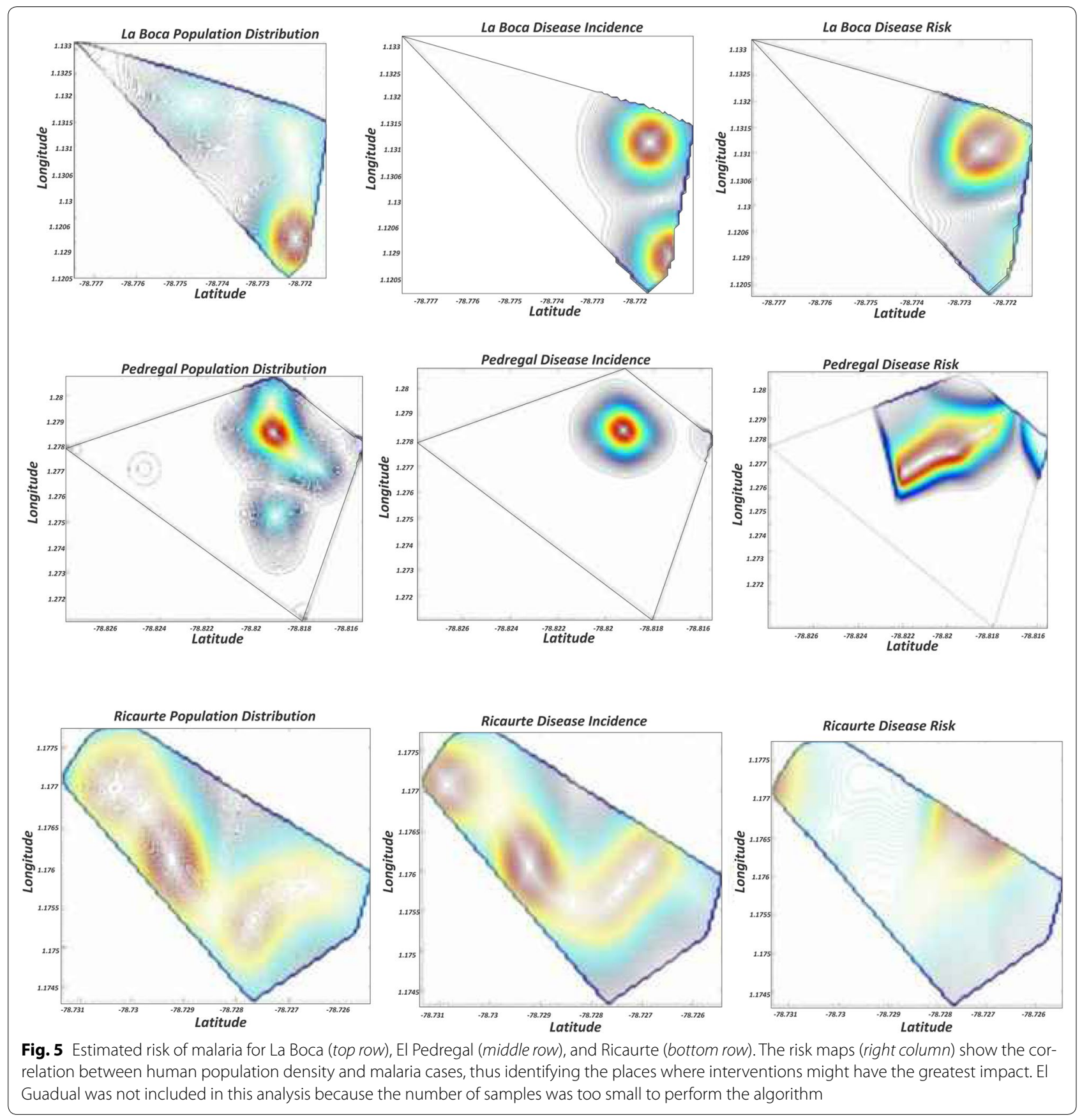

The periodic outbreaks, particularly the most recent one, appear to depend on several features. First, as most countries do, the National Malaria Control Programme (NMCP) of Ecuador uses microscopy and more recently RDT for malaria diagnosis. Although these two methods have great value for passive case detection of symptomatic cases, they show very limited sensitivity to detect asymptomatic cases which frequently display submicroscopic parasitaemia levels. Second, the intense population mobility from and to Colombia, may contribute to frequent reintroductions of malaria parasites. These and other issues may slow down the elimination process.

In the last several years there has been an increasing number of studies indicating the presence of asymptomatic submicroscopic malaria cases in all endemic areas of the world; unfortunately, in Ecuador there is a lack of studies addressing the malaria prevalence with more 
sensitive methods. Indeed, in contrast with the official records, this study confirmed a prevalence of asymptomatic infections between 2 and $13 \%$ in the different study sites, greater than expected and with a higher rate of $P$. vivax (6.9\%). The study also indicated a good level of malaria knowledge in the study communities, however, the surveyed population declared not to be participating significantly in control activities, even though the contribution of the endemic communities as well as that of several other malaria stakeholders to malaria elimination is considered essential.

Despite the fact that moving from malaria control to elimination, may appear as simple as intensifying control activities, elimination requires a significant sustained effort with critical strategic programme changes to ensure the goal of reaching zero cases.

Because the NMCP does not usually seek identification of asymptomatic infections, they frequently remain undiagnosed, and even if they are searched, thick smears have limited sensitivity. Furthermore, there is no policy about treatment of these infections, and therefore asymptomatic carriers may be contributing to maintaining the parasite transmission to Anopheles as suggested by previous studies [7, 9, 26]. In areas with low transmission levels, asymptomatics could be critical reservoirs in the maintenance of transmission, thus hampering elimination. The reported $7.5 \%$ prevalence by PCR in the study areas was higher than that reported for the northern coast of Peru (1.2\%) [20], but comparable to the prevalence recently found in the Colombian border (9.5\%) [7] and the Peruvian Amazon (10.9\%) [27], suggesting that even though the number of reported cases in Ecuador is lower than on the Colombian border, the transmission level may be similar. This finding is of great importance because, officially, Colombia is considered to be one of the countries with greater transmission in the Latin America region, while Ecuador is among those in pre-elimination phase. However, these results are similar to those reported previously from the Colombian coast, where PCR detected 26 times more parasites than microscopy when reactive case detection was used [7]. These results underscore the shortcomings of microscopy as a diagnosis technique and indicate that active surveillance in the area by the NMCP may not be enough to attain elimination. Moreover, all reported cases in this study were submicroscopic despite parasitaemia varying between 1 and 800 parasites/ $\mu$ l by PCR. It is likely that the amount of submicroscopic infections could be even higher because the PCR used here has a detection limit of $\sim 2$ parasites/ $\mu \mathrm{l}$ [7]. In this study, a real time PCR was used due to the convenience of the DNA transportation in filter paper. More sensitive methods such as RNA reverse transcriptase could have been used but the inability to preserve RNA was a limitation in the study setting.

On the other hand, the presence of asymptomatic cases indirectly indicates that despite the low transmission intensity the community has developed substantial levels of clinical immunity, even though overall, less than onethird of the population displayed positive titers to both parasite species. Even in El Pedregal where the highest reactivity was recorded, less than half of the study population was positive. The seroreactivity found was in general low, but the frequency of seropositive individuals appeared to correlate with the malaria prevalence, it was higher in El Pedregal which displayed greater number of submicroscopic infections. While this study used a basic serological approach, more information could have been obtained from an analysis of age dependent antibody response and IFAT in all the studied population.

It is surprising that, although Esmeraldas province is the only area of Ecuador still regularly reporting $P$. falciparum cases, in this study, P. vivax was by far the most prevalent parasite (94\% of infections against only 6\% caused by $P$. falciparum). In this province only four cases of $P$. vivax were reported in 2013 [6]. This finding might be explained by the high prevalence of asymptomatic $P$. vivax infections only detectable by q PCR, and is in contrast with a greater prevalence of $P$. falciparum reported in southern Colombia during the same period [7, 28]. A possible explanation for this could be related to the fact that a large part of the population may express reduced Duffy antigens on the surface of their RBCs as a result of heterozygous genotypes as has been shown in other populations that allow $P$. vivax infections at low parasitaemia and develop immunity against this parasite [29], consistent with the frequency of antibodies to $P$. vivax in El Pedregal and La Boca.

The high prevalence of $P$. vivax in an area where it is rarely reported brings new challenges from the treatment point of view. Ecuador uses a radical cure treatment that includes a 3-day chloroquine course and a 7 day primaquine treatment. The need for primaquine treatment for $P$. vivax, in an area not previously reported, will have important consequences in a possible elimination setting, considering that the status of glucose-6-phosphate dehydrogenase (G6PD) deficiencies is uncertain. Even though $P$. vivax treatment has been performed without G6PD deficiency testing in Ecuador, models predict that the north of the country, an area where P. vivax is rarely reported has a higher prevalence of G6PD deficiency than other areas where vivax infections are more common [30]. As elimination approaches, the treatment of asymptomatic $P$. vivax patients will need to go hand in hand with the determination of the G6PD status for each patient. 
The communities of El Pedregal, Ricaurte and La Boca with a greater historical exposure to malaria presented better knowledge about malaria but comparatively lower than in the adjacent coast of Colombia [31]. In contrast, in El Guadual, a community located towards the mountain side there was a lack of knowledge about malaria and no prevention practices were identified, this may correspond to recent introduction of malaria at these higher altitudes. Indeed, antibodies in this community indicated a lower previous exposure to the parasite than in the lowland study sites.

Although most people had a basic knowledge about malaria, practices to prevent malaria transmission were not very common. However, geo-referencing of malaria cases allowed mapping specific disease foci which facilitate targeting by control and elimination activities including education and community participation.

\section{Conclusions}

Taken together, the results of this study demonstrate higher malaria prevalence than expected in the north coast of Ecuador that may be related to environmental factors, with most cases corresponding to $P$. vivax asymptomatic and submicroscopic infections. Although this may be due to significant clinical immunity, it evidences diagnosis challenges for the NMCP and in addition may be contributing to the maintenance of transmission. The elimination goal in Ecuador would imply important changes including more sensitive diagnostic methods and active case detection, and probably community participation to eliminate mosquito breeding places among others.

\section{Authors' contributions}

FES, MA and SH conceived and designed the study; FES, AA, AFV, JG and SH wrote the manuscript; $A A, G V, A V, A C$, AP performed the experiments; $A A$, LEC performed field work; FES, AA, AV, GV, AC, JG, AA, YY, YB, MAH analysed the data. All authors read and approved the manuscript.

\section{Author details \\ ${ }^{1}$ Centro de Investigación para la Salud en América Latina, Escuela de Ciencias Biológicas, Pontificia Universidad Católica del Ecuador, Calle Pambacienda y San Pedro del Valle, Quito, Ecuador. ${ }^{2}$ Caucaseco Scientific Research Center, Cali, Colombia. ${ }^{3}$ Department of Mathematics, Institute of Bioinformatics, University of Georgia, Athens, GA, USA. ${ }^{4}$ Malaria Vaccine and Drug Develop- ment Center, Cali, Colombia. ${ }^{5}$ Ministerio de Salud Pública, Guayaquil, Ecuador. \\ ${ }^{6}$ School of Health, Universidad del Valle, Cali, Colombia.}

\section{Acknowledgements}

We would like to thank the participants from San Lorenzo county communities and the members of SNEM and the Ministry of Health of Ecuador who participated in field work. We thank Claudia Vera Arias and César Yumiseva for their help in the preparation of the figures.

\section{Competing interests}

The authors declare that they have no competing interests.

\section{Availability of data and materials}

The datasets used and/or analysed during the current study are available from the corresponding author on reasonable request.

\section{Ethics approval}

The study protocol was approved by the Ethical Review Committees of Pontificia Universidad Catolica del Ecuador (\# CBE-016-2013).

\section{Funding}

This research was funded by the Latin American ICEMR/CLAIM (NIH Grant Number U19AI089702), Pontificia Universidad Católica de Ecuador (Grants J13036, K13247 and L13247).

\section{Publisher's Note}

Springer Nature remains neutral with regard to jurisdictional claims in published maps and institutional affiliations.

Received: 6 May 2017 Accepted: 18 July 2017

Published online: 26 July 2017

\section{References}

1. SIVE-ALERTA. Gaceta epidemiológica Ecuador, semana 52, 2016. 2017.

2. WHO. World malaria report. World Health Organization, Geneva, Switzerland, 2016.

3. PAHO. Report on the situation of malaria in the Americas 2012. Panamerican Health Organization. 2013.

4. WHO. Eliminating malaria. World Health Organization, Geneva, Switzerland, 2016.

5. Saenz FE, Morton LC, Okoth SA, Valenzuela G, Vera-Arias CA, Velez-Alvarez $\mathrm{E}$, et al. Clonal population expansion in an outbreak of Plasmodium falciparum on the northwest coast of Ecuador. Malar J. 2015;13:497.

6. SIVEMAE 2 S. Ministerio de Salud Pública Reporte de casos de malaria en Ecuador. Guayaquil, Ecuador 2015.

7. Vallejo AF, Chaparro PE, Benavides Y, Alvarez A, Quintero JP, Padilla J, et al. High prevalence of sub-microscopic infections in Colombia. Malar J. 2015;14:201.

8. Bousema JT, Drakeley CJ, Kihonda J, Hendriks JC, Akim NI, Roeffen W, et al. A longitudinal study of immune responses to Plasmodium falciparum sexual stage antigens in Tanzanian adults. Parasite Immunol. 2007:29:309-17.

9. Vallejo AF, Garcia J, Amado-Garavito AB, Arevalo-Herrera M, Herrera S. Plasmodium vivax gametocyte infectivity in sub-microscopic infections. Malar J. 2016;15:48.

10. Lin JT, Saunders DL, Meshnick SR. The role of submicroscopic parasitemia in malaria transmission: what is the evidence? Trends Parasitol. 2014;30:183-90.

11. Barbosa S, Gozze AB, Lima NF, Batista CL, Bastos Mda S, Nicolete VC, et al. Epidemiology of disappearing Plasmodium vivax malaria: a case study in rural Amazonia. PLoS Negl Trop Dis. 2014:8:e3109.

12. da Silva-Nunes M, Moreno M, Conn JE, Gamboa D, Abeles S, Vinetz JM, et al. Amazonian malaria: asymptomatic human reservoirs, diagnostic challenges, environmentally driven changes in mosquito vector populations, and the mandate for sustainable control strategies. Acta Trop. 2012;121:281-91.

13. Cucunuba ZM, Guerra A, Rivera JA, Nicholls RS. Comparison of asymptomatic Plasmodium spp. infection in two malaria-endemic Colombian locations. Trans R Soc Trop Med Hyg. 2013;107:129-36.

14. Orjuela LI, Ahumada ML, Avila I, Herrera S, Beier JC, Quinones ML. Human biting activity, spatial-temporal distribution and malaria vector role of Anopheles calderoni in the southwest of Colombia. Malar J. 2015:14:256.

15. Pinault LL, Hunter FF. Malaria knowledge, concern, land management, and protection practices among land owners and/or managers in lowland versus highland Ecuador. Malar Res Treat. 2011;2011:765125.

16. Pinault LL, Hunter FF. Characterization of larval habitats of Anopheles albimanus, Anopheles pseudopunctipennis, Anopheles punctimacula, and Anopheles oswaldoi s.l. populations in lowland and highland Ecuador. J Vector Ecol. 2012:37:124-36.

17. Shute PG, Maryon M. An improved technique for staining malaria parasites with Giemsa Stain. Arch Roum Pathol Exp Microbiol. 1963:22:887-94.

18. Herrera S, Vallejo AF, Quintero JP, Arevalo-Herrera M, Cancino M, Ferro S. Field evaluation of an automated RDT reader and data management 
device for Plasmodium falciparum/Plasmodium vivax malaria in endemic areas of Colombia. Malar J. 2014;13:87.

19. Rougemont M, Van Saanen M, Sahli R, Hinrikson HP, Bille J, Jaton K. Detection of four Plasmodium species in blood from humans by $18 \mathrm{~S}$ rRNA gene subunit-based and species-specific real-time PCR assays. J Clin Microbiol. 2004:42:5636-43.

20. Rosas-Aguirre A, Llanos-Cuentas A, Speybroeck N, Cook J, Contreras-Mancilla J, Soto V, et al. Assessing malaria transmission in a low endemicity area of north-western Peru. Malar J. 2013;12:339.

21. Herrera S, Gomez A, Vera O, Vergara J, Valderrama-Aguirre A, Maestre A, et al. Antibody response to Plasmodium vivax antigens in Fy-negative individuals from the Colombian Pacific coast. Am J Trop Med Hyg. 2005;73:44-9.

22. Valderrama-Aguirre A, Quintero G, Gomez A, Castellanos A, Perez Y, Mendez $F$, et al. Antigenicity, immunogenicity, and protective efficacy of Plasmodium vivax MSP1 PV200l: a potential malaria vaccine subunit. Am J Trop Med Hyg. 2005;73:16-24.

23. Storti-Melo LM, Souza-Neiras WC, Cassiano GC, Taveira LC, Cordeiro AJ, Couto VS, et al. Evaluation of the naturally acquired antibody immune response to the Pv200L N-terminal fragment of Plasmodium vivax merozoite surface protein-1 in four areas of the Amazon Region of Brazil. Am J Trop Med Hyg. 2011;84:58-63.

24. Lopez JA, Gonzalez JM, Kettner A, Arevalo-Herrera M, Herrera S, Corradin $\mathrm{G}$, et al. Synthetic polypeptides corresponding to the non-repeat regions from the circumsporozoite protein of Plasmodium falciparum: recognition by human T-cells and immunogenicity in owl monkeys. Ann Trop Med Parasitol. 1997;91:253-65.
25. Bongfen SE, Ntsama PM, Offner S, Smith T, Felger I, Tanner M, et al. The $\mathrm{N}$-terminal domain of Plasmodium falciparum circumsporozoite protein represents a target of protective immunity. Vaccine. 2009;27:328-35.

26. Harris I, Sharrock WW, Bain LM, Gray KA, Bobogare A, Boaz L, et al. A large proportion of asymptomatic Plasmodium infections with low and sub-microscopic parasite densities in the low transmission setting of Temotu Province, Solomon Islands: challenges for malaria diagnostics in an elimination setting. Malar J. 2010;9:254.

27. Rosas-Aguirre A, Speybroeck N, Llanos-Cuentas A, Rosanas-Urgell A, Carrasco-Escobar G, Rodriguez H, et al. Hotspots of malaria transmission in the Peruvian Amazon: rapid assessment through a parasitological and serological survey. PLoS ONE. 2015;10:0137458.

28. Vasquez-Jimenez JM, Arevalo-Herrera M, Henao-Giraldo J, Molina-Gomez $\mathrm{K}$, Arce-Plata M, Vallejo AF, et al. Consistent prevalence of asymptomatic infections in malaria endemic populations in Colombia over time. Malar J. 2016;15:70.

29. Zimmerman PA, Woolley I, Masinde GL, Miller SM, McNamara DT, Hazlett $\mathrm{F}$, et al. Emergence of $\mathrm{FY}^{*} \mathrm{~A}($ null) in a Plasmodium vivax-endemic region of Papua New Guinea. Proc Natl Acad Sci USA. 1999;96:13973-7.

30. Howes RE, Piel FB, Patil AP, Nyangiri OA, Gething PW, Dewi M, et al. G6PD deficiency prevalence and estimates of affected populations in malaria endemic countries: a geostatistical model-based map. PLoS Med. 2012;9:1001339.

31. Forero DA, Chaparro PE, Vallejo AF, Benavides Y, Gutierrez JB, Arevalo-Herrera $\mathrm{M}$, et al. Knowledge, attitudes and practices of malaria in Colombia. Malar J. 2014;13:165.

\section{Submit your next manuscript to BioMed Central and we will help you at every step:}

- We accept pre-submission inquiries

- Our selector tool helps you to find the most relevant journal

- We provide round the clock customer support

- Convenient online submission

- Thorough peer review

- Inclusion in PubMed and all major indexing services

- Maximum visibility for your research

Submit your manuscript at www.biomedcentral.com/submit
() Biomed Central 